\title{
Minimization of Reactive Power Exchange at the DSO/TSO interface: Öland case
}

\author{
Michał Tomaszewski, Stefan Stanković \\ Electric Power and Energy Systems \\ KTH Royal Institute of Technology \\ Stockholm, Sweden \\ Stanko@kth.se
}

\author{
Ingmar Leisse \\ E.On Energidistribution $A B$ \\ Malmö, Sweden \\ Ingmar.Leisse@eon.se
}

\author{
Lennart Söder \\ Electric power and energy systems \\ KTH Royal Institute of Technology \\ Stockholm, Sweden \\ lsod@kth.se
}

\begin{abstract}
A rising penetration of renewable energy sources in electric power grids is both a challenge and an opportunity to utilize its potential to stabilize operation of future power systems. Bi-directional flows between distribution and transmission systems can cause significant problems with keeping the voltages and reactive power in grids within permissible levels. This paper addresses the problem of reactive power exchange between the distribution system of Öland and the mainland Swedish electricity grid. Wind turbine generators with the capacity that highly exceeds total demand in Öland, are used to minimize absolute reactive power exchanged at the point of connection. This is done by applying droop control functions for reactive support to the wind turbines. Results indicate that the controllability of the reactive power support from wind turbine generators can keep the reactive power flow minimized at the point of connection and simultaneously diminish the active power losses in the system. The analysis in this paper has been done using the PSS/E software.
\end{abstract}

Index Terms-Reactive Power, Power Flow Analysis, Smart Grids, Droop Control

\section{INTRODUCTION}

In Sweden, at the end of year 2017, almost 6.7 GW of total's system capacity was coming from on-shore and off-shore wind farms [1]. Larger amounts of decentralized generation installed in lower voltage grids can cause many new and uncommon effects. One of which is reversed power flows from lower to higher voltage grids. This can lead to unwanted voltage increase under low load conditions. Shunt capacitors or shunt reactors are needed to supply or absorb extra reactive power and to keep the voltages and currents within permissible limits [2]. Another problem that appears are the excessive levels of reactive power exchange between the grids of different voltage levels exceeding ENTSO-E recommended limits [3]. Both of these problems can be solved using reactive power capabilities of wind farms [4]-[7].

ENTSO-E and other EU organizations force new legislation stating connection demands for generators [8]. Power factor equal to 1 at the output of the generator is often not possible or difficult to achieve, especially in rural areas, as a voltage rise is a serious issue. Excess absorption of reactive power by generators combined with weak volt-ampere reactive backing capability of local transmission grid might result in poor voltage profiles or depletion of reactive power reserves leading to instabilities [9] [10]. There is a lack of regulation that would lead to more flexible behaviour of the electric power grid.
In some of the countries, there is a need for the distribution system operator (DSO) to keep the power factor at the point of connection (POC) close to 1 [3]. For example, in Spain, during peak periods, the power exchanged between transmission and distribution systems has to have power factor of $\cos (\varphi)>$ 0.95. In the same time, during off-peak periods DSOs are obligated to not exchange reactive power with transmission system operator (TSO) [3]. In Germany, bilateral agreements between TSO and DSO are used to specify the reactive power flow limits at the point of interface between two systems [3]. At the time of writing, limits on reactive power exchange between DSO and TSO are not strictly applied in Sweden.

Limitation of reactive power exchange at POC has been a focus of many papers. Most solutions addressing this problem are well-known droop control methods [11]-[13]. Other solutions [14] [15] use particle swarm optimization and optimal power flow model with predictive control for power management of $110 \mathrm{kV}$ grid. Adaptation of power factor and transformer tap changer settings to minimize the reactive power imported to distribution grid is proposed by [16]. Good examples of reactive power potential of distribution and local transmission grids have been presented in [17]-[21].

This paper analyses potential to control reactive power exchange between Öland distribution grid and mainland Swedish transmission system using $\mathrm{Q}(\mathrm{P})$ droop controllers applied to the wind turbine generators (WTG) located on Öland island. Based on reactive power compensation objectives, two options for droop controllers tuning are presented: local and global. Results indicate that presented droop control strategies can address the problem of extensive reactive power exchange between medium and high voltage grids. Utilization of wind farms to support the reactive power in the distribution grid results in decrease in active power losses in the system and significantly improves the reactive power flow at the POC. Further adjustment of droop curves could fully employ reactive power contribution coming from the WTGs.

\section{DROOP CONTROLLERS}

To minimize the reactive power exchanged between DSO and TSO droop control strategies, two objective functions were used:

A. Local objective control methods - reactive power is compensated locally, i.e. within vicinity of the wind farm, 
B. Global objective control methods - reactive power is compensated globally, i.e. within certain voltage level/pricing area.

Two case studies have been done, with and without STATCOM capabilities of the wind farms. Both control methods are droop-based schemes.

\section{A. Local objective $Q(P)$ droop controller}

The control system with a local objective function has been dedicated to compensate the reactive power locally in the wind farms vicinity. Local objective droop control algorithm intended to compensate reactive power as a function of active power generated by individual wind farms. With high active power production of wind farms, reactive power losses in the area starts increasing. Thus, droop curve has been designed that maximum positive contribution by wind farms (supply of reactive power) was obtained when active power production was at the highest (Fig. 1).

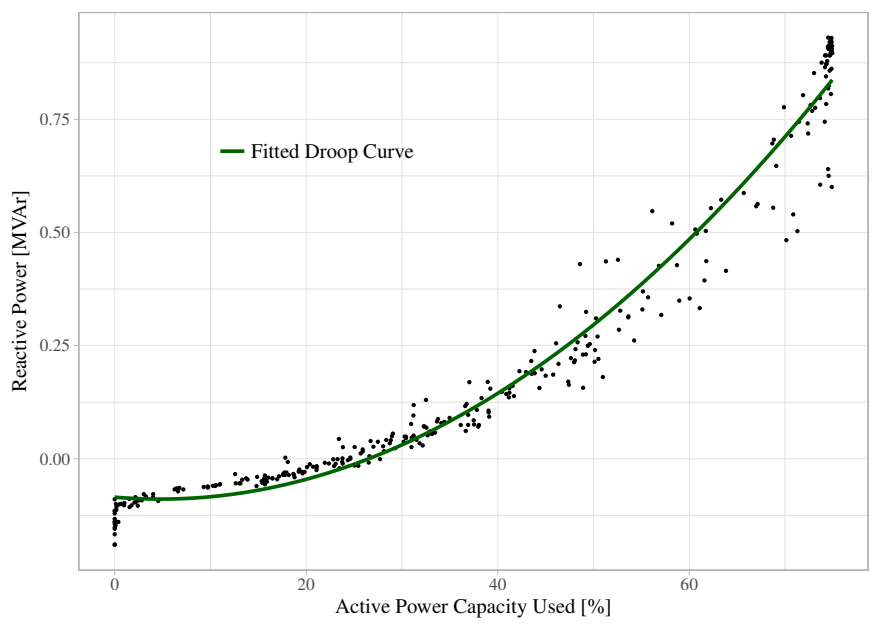

Fig. 1: Example of initial droop curve created based on the relation between reactive power exchanged in wind farm vicinity and active power capacity used of that wind park.

Contribution from each individual wind farm was based on its capacity. In the case of wind park consisting of 2 wind generators of total capacity $10 \mathrm{MW}$ (generator 1 of $6 \mathrm{MW}$ and generator 2 of $4 \mathrm{MW}$ ), maximum reactive power support by $6 \mathrm{MW}$ generator would be up to $60 \%$ of total reactive power support from this particular cluster of wind generators. Thus, depending on the actual active power contribution of the wind farm, reactive power was adjusted accordingly.

Two cases are presented for each of the control method objectives. Droop curve $(\mathrm{Q}(\mathrm{P}))$ relation to offset the reactive power was dependent whether STATCOM functionality was installed within wind turbine generators or not. Reactive power support, for wind farms without STATCOMs, started at $2 \%$ of active power capacity used. Wind parks with STATCOM functionality, were able to absorb or supply reactive power at any time, independent of actual active power production.

\section{B. Global objective $Q(P)$ droop controller}

The second control scheme aimed to compensate reactive power at the POC. Global objective of this droop controller was to minimize the absolute reactive energy flowing in and out of the whole distribution system. As in the case of local droop control strategy, the peak (highest reactive power contribution) was when active power production of the Öland's wind farms was the highest. Lowest point in reactive power contribution (absorption of reactive power by wind farms) was accompanied with the lowest production of active power by Öland's generators, Fig. 2.

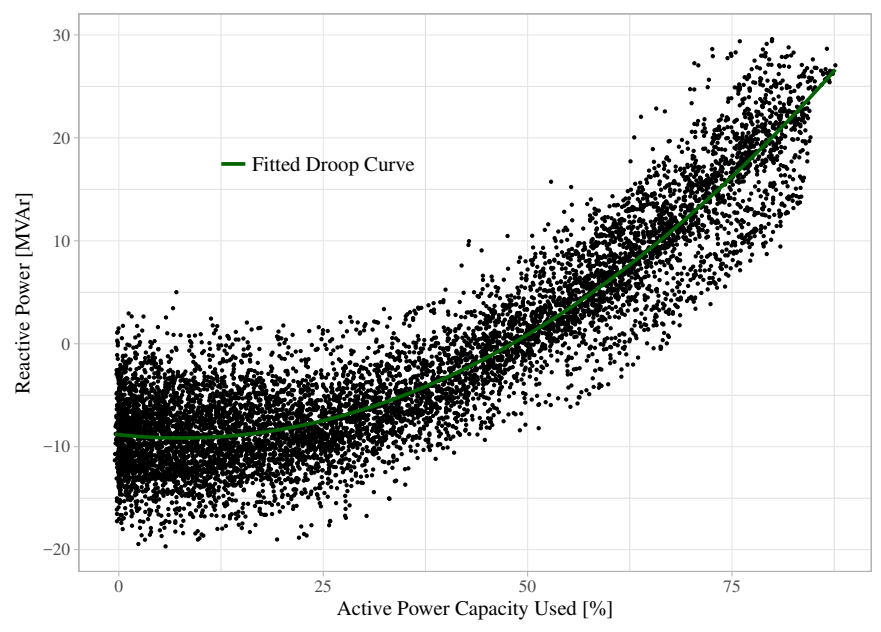

Fig. 2: Example of initial droop curve created based on the relation between reactive power exchanged at POC and active power capacity used in wind parks.

First step in design of the droop controller was to find the droop curve describing relation between the reactive power exchanged at POC and active power generated by all WTGs. Initial relation between active power production and reactive power exchanged at POC was found by coefficient of determination $\left(\mathrm{R}^{2}\right.$ regression). Reactive power contribution was assigned base on percentage of active power capacity used. Wind farms contributed accordingly, in order to minimize the reactive power exchanged at POC. Thus, for example, one wind farm's active power output was at the level of $50 \%$ of its capacity. This particular wind farm contributed in total $50 \%$ of its maximum reactive power contribution. If, in the same hour, other wind farm was generating active power at $30 \%$ of its capacity, the reactive power was at the level of $30 \%$ of its maximum reactive power contribution. This procedure was implemented in all wind farms in the system.

\section{Description of The System}

\section{A. Model}

Analyzed grid mirrors a real part of the Swedish electric grid. All data presented in the paper are real values collected by measuring devices throughout year 2017. Total capacity of WTGs and minor generators installed amounted to $173.5 \mathrm{MW}$, out of which 136.1 MW was connected to dedicated buses 
and was considered as controllable in the PSS/E model. The presented grid was connected to the rest of the electric power system through two $130 \mathrm{kV}$ multi-section lines of capacity 280 MVA each. Öland distribution grid model consists of 98 buses (56 of non-generating type, 41 of generating type, 1 of swing type). Swing bus has been located at $130 \mathrm{kV}$ substation and was used to render rest of the electric grid as Thevenin equivalent circuit keeping voltage at that point to 1 p.u.. Out of 41 generating buses, 10 of them were of mixed type and 31 were dedicated to connect wind power units exclusively. Reactive power support was manageable until reaching upper and lower reactive power generation limits $\left(Q_{T}\right.$ and $\left.Q_{B}\right)$, according to (1).

$$
Q_{T}<Q_{\text {contribution }}<Q_{B}
$$

In area of interest there were two capacitors (of total compensation of 4.25 MVAr) connected to the lower voltage part of the grid. For the simulation purposes all capacitors were turned-off and the value of the compensation was offset from the generator or load located at the bus where capacitor was connected. In the system there were 31 lines of $55 \mathrm{kV}, 2$ lines were of $33 \mathrm{kV}, 12$ lines were of $22 \mathrm{kV}, 11$ lines of $11 \mathrm{kV}$. In the system there were 55 transformers (51 two-winding, 4 three-winding), connecting buses of different voltage levels.

\section{B. Time-series data}

Time-series data used for the simulation was given in hourly mean value. System's generators, for most of the time were consumers of reactive power with peaks of almost $7 \mathrm{MVAr}$ in fourth quarter of the year. In early January, consumption of reactive power by loads reached value of more than 12 MVAr. Active power generation peaked to $119.3 \mathrm{MW}$ in windy periods, giving capacity utilization ratio of $87.6 \%$. Reactive power generation reached levels of 2 MVAr (which was result of capacitive characteristics of cables connecting the wind farms).

\section{Reactive power exchanged at POC-Reference Case}

Yearly variations of exchanged active and reactive power at POC are shown on Fig. 3. Two red lines represent potentially imposed limits on the amounts of reactive power exchange at the border of DSO/TSO. In Fig. 3, positive value on Xaxis represents import of the reactive power to Öland and negative value stands for export of the reactive power from Öland. Positive value on y-axis stands for import of active power to Öland and negative value stands for export of active power from Öland.

\section{Simulations And Results}

In order to control reactive power at POC in between \pm 5 MVAr limits shown on Fig. 3, droop control strategies described in Section II are applied to the analyzed system.

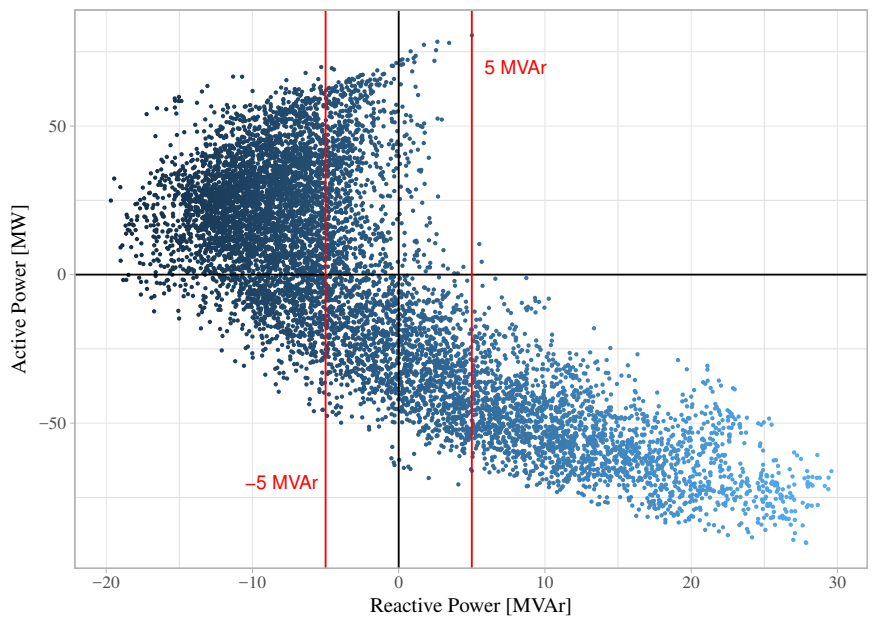

Fig. 3: Active against reactive power exchange at the point of connection at $130 \mathrm{kV}$ substation (swing bus). Reference case.

1) Local objective droop controllers results: To obtain the most accurate description of the relation between active power production from wind farms and associated increased reactive power losses in the grid, set of droop curves were generated. They were designed base on month of the year and time of a day (7 a.m. to 22 p.m. and from 23 p.m. to 6 a.m.). Finally 360 different droop curves ( 15 generators, 12 months, 2 tariffs) were activated base on time of the year and time of a day.

The system with implemented $\mathrm{P}(\mathrm{Q})$ curves was simulated throughout 8760 hours of the year. Results of the simulations are presented in tables I, II and III.

Implementation of local objective droop control method resulted, in the case of STATCOM and without STATCOM, in decreased active energy losses by $653 \mathrm{MWh}$ and $643 \mathrm{MWh}$. Mean value of reactive power export to the overlying grid increased from -1.7 MVAr to value below -3 MVAr for both scenarios. Standard deviation (SD) dropped from $10 \mathrm{MVAr}$ to slightly below 6 MVAr. Table II, shows that the effects of

TABLE I: Results of implementation of local objective control scheme. B-Base, S-STATCOM, NS-without STATCOM.

\begin{tabular}{llll} 
& $\mathbf{2 0 1 7}(\mathbf{B})$ & $\mathbf{2 0 1 7}(\mathbf{S})$ & $\mathbf{2 0 1 7}(\mathbf{N S})$ \\
\hline Active Energy Exchanged [MWh] & -42749 & -43402 & -43392 \\
Mean Q Exchanged [MVAr] & -1.7 & -3.2 & -3.8 \\
SD Q Exchanged [MVAr] & 10.0 & 5.7 & 5.9 \\
\hline
\end{tabular}

local objective droop control scheme are positive. Number of hours within \pm 5 MVArh limit increased by almost $50 \%$ in both cases.

TABLE II: Number of hours within \pm 5 MVAr and $\pm 10 \mathrm{MVAr}$ at POC. Local objective control scheme. B-Base, S-STATCOM, NS-without STATCOM.

\begin{tabular}{llll} 
& $\mathbf{2 0 1 7}$ (B) & $\mathbf{2 0 1 7}$ (S) & $\mathbf{2 0 1 7}$ (NS) \\
\hline Within \pm 5 MVAr [\%] & 27.5 & 50.8 & 46.1 \\
Within \pm 10 MVAr [\%] & 64.4 & 87.6 & 84.6 \\
\hline
\end{tabular}

Total reactive energy exceeding $\pm 5 \mathrm{MVAr}$ dropped from 37096 MVArh to 14884 MVArh (S) and 17503 MVArh (NS) 
as presented in Table III.

TABLE III: Absolute value of reactive energy exceeding $\pm 5 \mathrm{MVAr}$ and \pm 10 MVAr at POC. Local objective control scheme. B-Base, S-STATOM, NS-without STATCOM.

\begin{tabular}{llll} 
& $\mathbf{2 0 1 7}$ (B) & $\mathbf{2 0 1 7}$ (S) & $\mathbf{2 0 1 7}$ (NS) \\
\hline Exceeding \pm 5 MVAr [MVArh] & 37096 & 14884 & 17503 \\
Exceeding \pm 10 MVAr [MVArh] & 13311 & 2553 & 3154 \\
\hline
\end{tabular}

Active and reactive power flow at POC in 2017 is shown on Fig. 4 and Fig. 5.

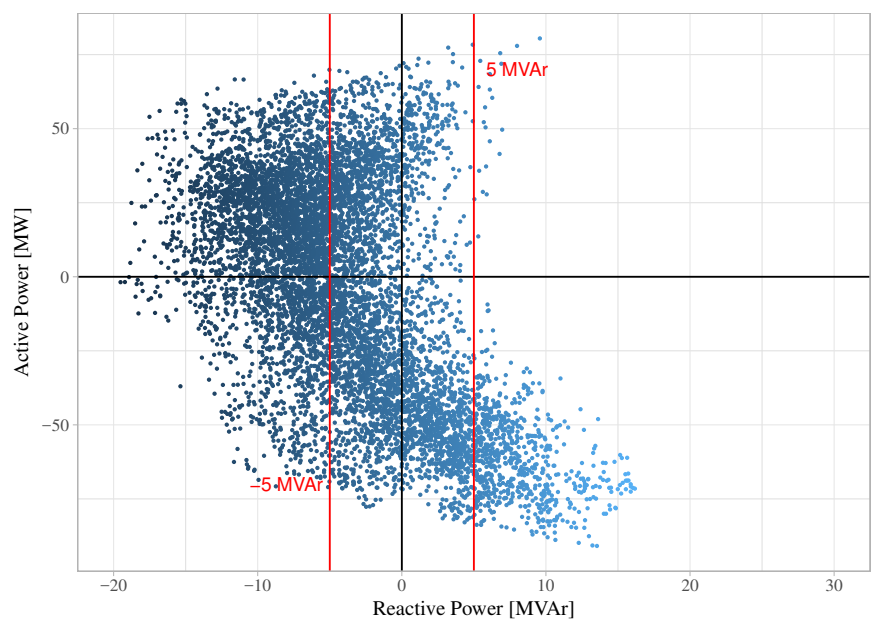

Fig. 4: Reactive power exchanged at POC. Local objective control scheme. Scenario without STATCOM.

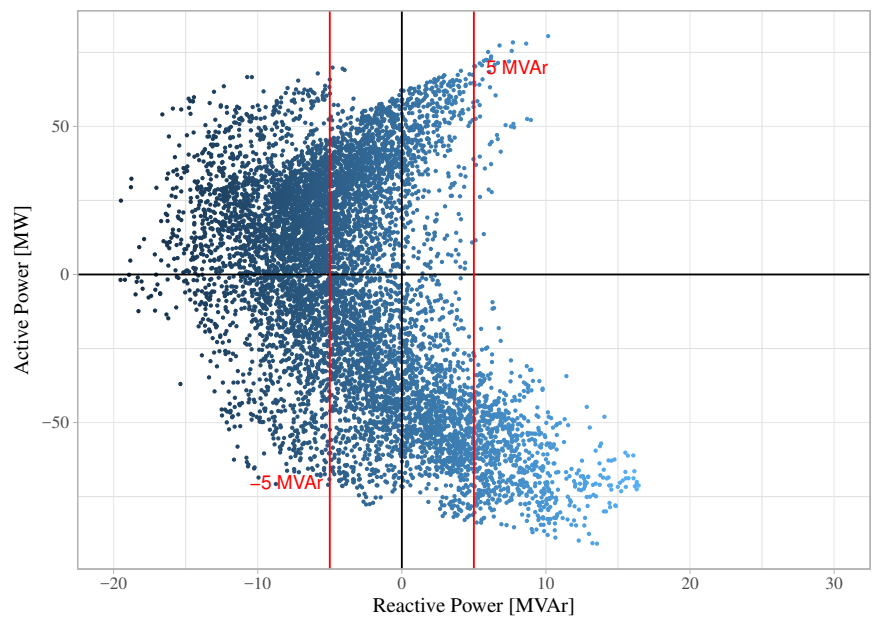

Fig. 5: Reactive power exchanged at POC. Local objective control scheme. Scenario with STATCOM.

2) Global objective droop controllers results: Initial relation between active power flowing out of wind generators and reactive power at POC was adjusted depending on time of the year and time of the day. As a result, 24 different droop curves were created to most accurately represent real conditions. The algorithm activated droop curves in each of the wind generators independently and at the same time, depending on time of the day and month of the year.

Obtained $\mathrm{Q}(\mathrm{P})$ global objective droop curves were tested on the analyzed system. Results are shown in tables IV, V,
VI. Implementation of global objective droop control method

TABLE IV: Results of implementation of global objective control scheme. B-Base, S-STATCOM, NS-without STATCOM

\begin{tabular}{llll} 
& $\mathbf{2 0 1 7}(\mathbf{B})$ & $\mathbf{2 0 1 7}(\mathbf{S})$ & $\mathbf{2 0 1 7}(\mathbf{N S})$ \\
\hline Active Energy Exchanged [MWh] & -42749 & -42947 & -42920 \\
Mean Q Exchanged [MVAr] & -1.7 & -1.9 & -1.9 \\
SD Q Exchanged [MVAr] & 10.0 & 3.9 & 4.7 \\
\hline
\end{tabular}

resulted in decreased active energy losses by $198 \mathrm{MWh}(\mathrm{S})$ and $171 \mathrm{MWh}(\mathrm{NS})$. Mean value of Q decreased from -1.7 MVAr to -1.9 MVAr for both scenarios. Standard deviation dropped from 10 MVAr to 3.9 MVAr in STATCOM scenario and 4.7 MVAr when STATCOMs were not included in the simulation.

TABLE V: Number of hours within the \pm 5 MVAr and \pm 10 MVAr at POC. Global objective control scheme. B-Base, S-STATCOM, NS-without STATCOM

\begin{tabular}{llll} 
& $\mathbf{2 0 1 7}$ (B) & $\mathbf{2 0 1 7}$ (S) & $\mathbf{2 0 1 7}$ (NS) \\
\hline Within \pm 5 MVAr [\%] & 27.5 & 77.8 & 68.5 \\
Within \pm 10 MVAr [\%] & 64.4 & 96.9 & 94.5 \\
\hline
\end{tabular}

Table V shows that the effects of global objective droop control method are more positive comparing with local objective control method. Number of hours within \pm 5 MVAr limit raised to $77.8 \%$ and $68.5 \%$. Total reactive energy exceeding the limit of \pm 5 MVAr dropped from 37096 MVArh to 4883 MVArh (S) and 7987 MVArh (NS), as seen in Table VI. Scatter

TABLE VI: Absolute value of reactive energy exceeding \pm 5 MVAR and \pm 10 MVAr at POC. Global objective control scheme. B-Base, S-STATCOM, NS-without STATCOM

\begin{tabular}{llll} 
& $\mathbf{2 0 1 7}$ (B) & $\mathbf{2 0 1 7}$ (S) & $\mathbf{2 0 1 7}$ (NS) \\
\hline Exceeding \pm 5 MVAr [MVArh] & 37096 & 4883 & 7987 \\
Exceeding \pm 10 MVAr [MVArh] & 13311 & 430 & 866 \\
\hline
\end{tabular}

plots of exchanged active and reactive power at POC during year 2017 with implemented global objective droop controllers are shown on Fig. 6 and Fig. 7.

\section{CONCLUSIONS AND Future WORK}

Most promising method, considering simplicity is the local droop control method. Drop in standard deviation by almost $50 \%$ enables to easier offset the remaining reactive power at the POC. Global objective droop control scheme was able to decline the total reactive power flowing out of the bigger area of the grid. Standard deviation and absolute value of reactive power exchanged with the swing bus decreased by $60 \%$. To offset the remaining reactive power, capacitor and reactor banks can be added.

Net flow of active power flowing out of the area of interest has been increased after implementation of proposed control schemes. This leads to extra profit to DSO and could create additional incentive to implement control schemes. The results are promising but show space for improvement. Both, local and global objective droop control methods could be further optimized by imposing new objectives such as minimization of active power losses. Global objective droop control algorithm 


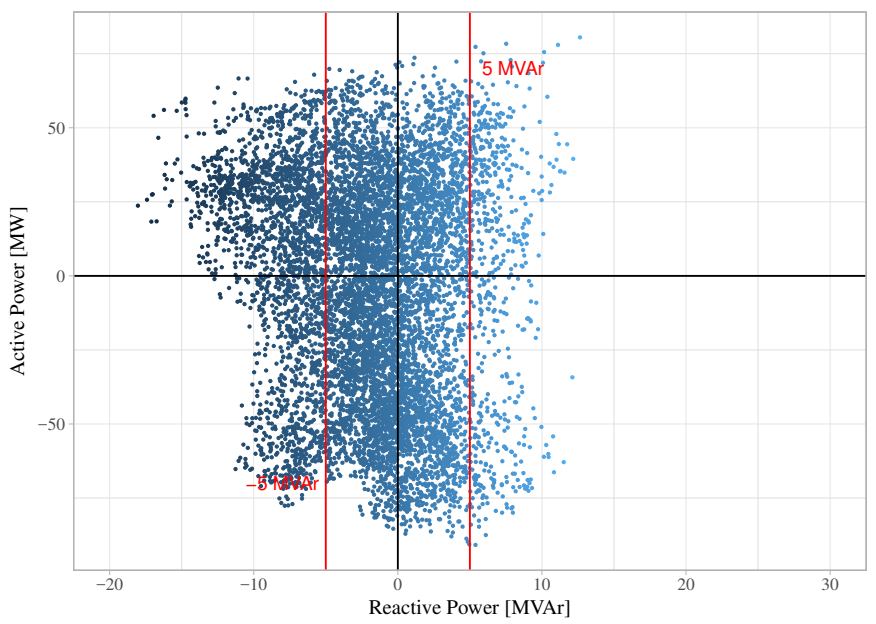

Fig. 6: Reactive power exchanged at POC. Global objective Q(P) control scheme. Scenario without STATCOM.

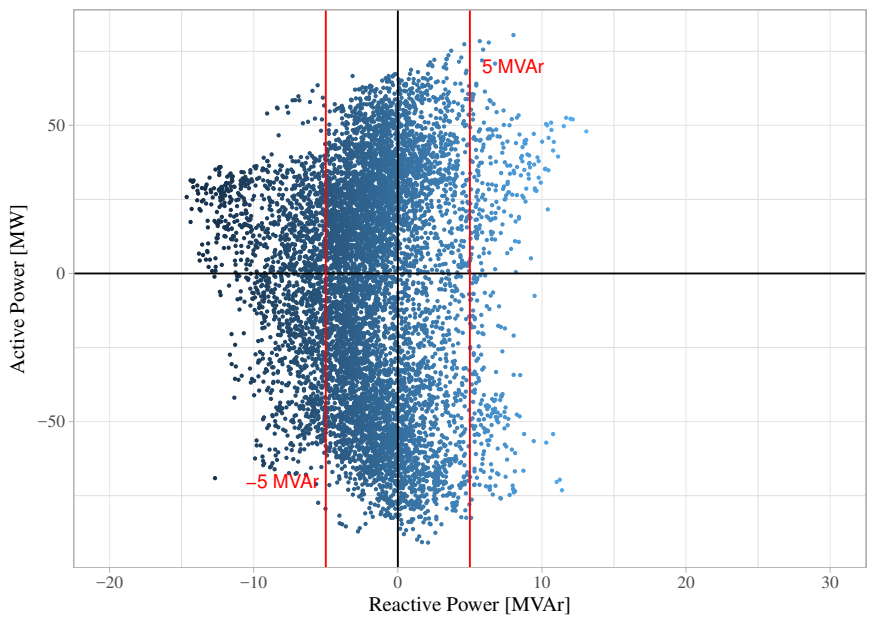

Fig. 7: Reactive power exchanged at POC. Global objective $\mathrm{Q}(\mathrm{P})$ control scheme. Scenario with STATCOM.

could be better tuned by analysis of individual wind farms and their contribution to the reactive power support. In local objective control schemes, additional parameters characterizing loads connected to the grid in vicinity of the wind farm could improve the accuracy of this method. Pilot project would be needed to evaluate real potential of presented solutions.

\section{REFERENCES}

[1] W. Europe, "Wind in power 2017. annual combined onshore and offshore wind energy statistics," windeurope. org/wp-content/uploads/files/aboutwind/statistics/WindEurope-Annual-Statistics-2017. pdf, 2018.

[2] G. Chavan, S. Acharya, S. Bhattacharya, D. Das, and H. Inam, "Application of static synchronous series compensators in mitigating ferranti effect," vol. 2016-. IEEE, July 2016, pp. 1-5.

[3] ENTSO-E, "Reactive power management at t-d interface," Online, 2016.

[4] S. Stanković and L. Söder, "Analytical estimation of reactive power capability of a radial distribution system," IEEE Transactions on Power Systems, vol. 33, no. 6, pp. 6131-6141, Nov 2018.

[5] — , "Identification of reactive power provision boundaries of a distribution grid with dfigs to a transmission grid," 09 2017, pp. 1-6.

[6] H. Karbouj and Z. H. Rather, "Voltage control ancillary service from wind power plant," IEEE Transactions on Sustainable Energy, pp. 1-1, 2018.
[7] D. F. Opila, A. M. Zeynu, and I. A. Hiskens, "Wind farm reactive support and voltage control," in 2010 IREP Symposium Bulk Power System Dynamics and Control - VIII (IREP), Aug 2010, pp. 1-10.

[8] "Commission regulation (eu) 2016/631 of 14 april 2016 establishing a network code on requirements for grid connection of generators," 2016. [Online]. Available: http://data.europa.eu/eli/reg/2016/631/oj

[9] E. Vittal, A. Keane, and M. O'Malley, "Varying penetration ratios of wind turbine technologies for voltage and frequency stability," in Power and Energy Society General Meeting-Conversion and Delivery of Electrical Energy in the 21st Century, 2008 IEEE. IEEE, 2008, pp. $1-6$.

[10] A. Keane, L. F. Ochoa, C. Dent, and G. P. Harrison, "Optimal voltage control settings for wind power," in Proc. 2009 International Conference on Electricity Distribution (CIRED). IET, 2009, pp. 1-5.

[11] P. Franz, I. Talavera, J. Hanson, and I. Sgoff, "Optimized regulation of dispersed generation units for minimization of reactive power consumption," in Innovative Smart Grid Technologies Conference (ISGT), 2015 IEEE Power \& Energy Society. IEEE, 2015, pp. 1-5.

[12] A. Samadi, E. Shayesteh, R. Eriksson, B. Rawn, and L. Söder, "Multiobjective coordinated droop-based voltage regulation in distribution grids with pv systems," Renewable energy, vol. 71, pp. 315-323, 2014.

[13] U. B. Tayab, M. A. B. Roslan, L. J. Hwai, and M. Kashif, "A review of droop control techniques for microgrid," Renewable and Sustainable Energy Reviews, vol. 76, pp. 717-727, 2017.

[14] R. I. Cabadag, U. Schmidt, and P. Schegner, "The voltage control for reactive power management by decentralized wind farms," in PowerTech, 2015 IEEE Eindhoven. IEEE, 2015, pp. 1-6.

[15] D. S. Stock, A. Venzke, T. Hennig, and L. Hofmann, "Model predictive control for reactive power management in transmission connected distribution grids," in Power and Energy Engineering Conference (APPEEC), 2016 IEEE PES Asia-Pacific. IEEE, 2016, pp. 419-423.

[16] L. F. Ochoa, A. Keane, and G. P. Harrison, "Minimizing the reactive support for distributed generation: Enhanced passive operation and smart distribution networks," IEEE Transactions on Power Systems, vol. 26, no. 4, pp. 2134-2142, 2011.

[17] C. Espejo Marín and R. García Marín, "Agua y energía: producción hidroeléctrica en españa," Investigaciones Geográficas (Esp), no. 51, 2010.

[18] D. Maihöfner, I. Talavera, J. Hanson, C. Bott, and F. Oechsle, "Vertical reactive power flexibility through distributed energy resources for a reactive energy management," in Compatibility, Power Electronics and Power Engineering (CPE-POWERENG), 2017 11th IEEE International Conference on. IEEE, 2017, pp. 100-105.

[19] F. Hinz and D. Moest, "Techno-economic evaluation of $110 \mathrm{kv}$ grid reactive power support for the transmission grid," IEEE Transactions on Power Systems, 2018.

[20] N. Leemput, F. Geth, J. V. Roy, J. Büscher, and J. Driesen, "Reactive power support in residential lv distribution grids through electric vehicle charging," Sustainable Energy, Grids and Networks, vol. 3, pp. 24 - 35, 2015. [Online]. Available: http://www.sciencedirect.com/science/article/pii/S2352467715000375

[21] D. Xie, Z. Xu, L. Yang, J. Østergaard, Y. Xue, and K. P. Wong, "A comprehensive lvrt control strategy for dfig wind turbines with enhanced reactive power support," IEEE Transactions on Power Systems, vol. 28, no. 3, pp. 3302-3310, 2013. 